Network Working Group

Request for Comments: 2605

Obsoletes: 1567

Category: Standards Track
G. Mansfield Cyber Solutions Inc. S. Kille MessagingDirect Ltd. June 1999

Directory Server Monitoring MIB

Status of this Memo

This document specifies an Internet standards track protocol for the Internet community, and requests discussion and suggestions for improvements. Please refer to the current edition of the "Internet Official Protocol Standards" (STD 1) for the standardization state and status of this protocol. Distribution of this memo is unlimited.

Copyright Notice

Copyright (C) The Internet Society (1999). All Rights Reserved.

Abstract

This memo defines a portion of the Management Information Base (MIB) for use with network management protocols in the Internet community. This memo obsoletes RFC 1567, "X.500 Directory Monitoring MIB". This memo extends that specification to a more generic MIB for monitoring one or more directory servers each of which may support multiple access protocols. The MIB defined in this memo will be used in conjunction with the NETWORK-SERVICES-MIB [19] for monitoring Directory Servers.

Table of Contents

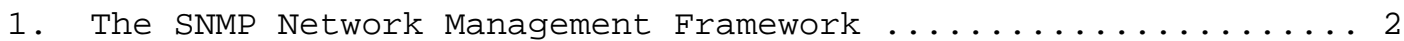

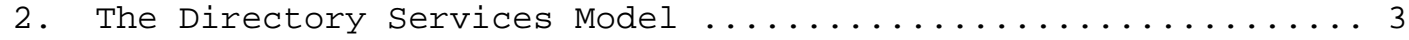

3. MIB Model for Directory Management .................. 4

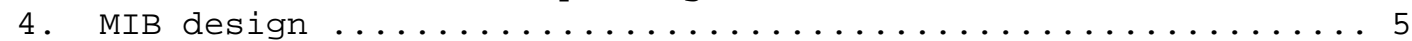

5. The Directory Server Monitoring MIB ............... 5

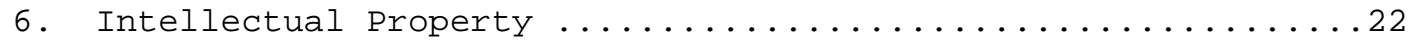

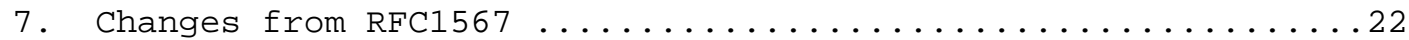

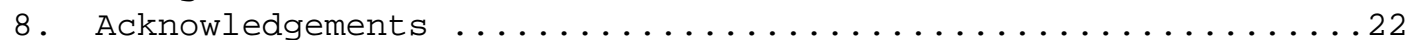

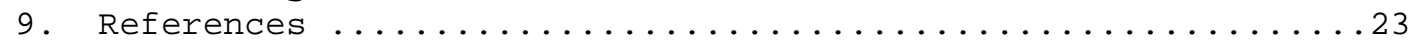

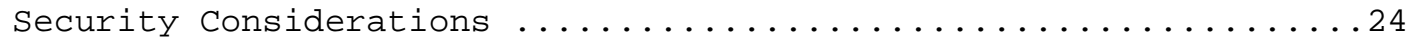

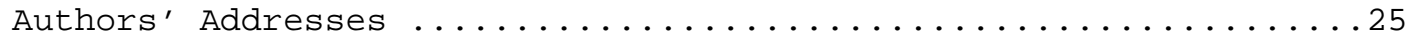

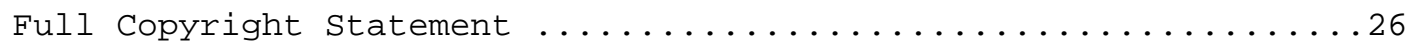


1. The SNMP Network Management Framework

The SNMP Network Management Framework presently consists of five major components:

o An overall architecture, described in RFC 2571 [1].

- Mechanisms for describing and naming objects and events for the purpose of management. The first version of this structure of Management Information (SMI) is called SMIV1 and described in $\mathrm{STD} 16, \mathrm{RFC} 1155$ [2], STD 16, RFC 1212 [3] and RFC 1215 [4]. The second version, called SMIv2, is described in STD 58, RFC 2578 [5], RFC 2579 [6] and RFC 2580 [7].

- Message protocols for transferring management information. The first version of the SNMP message protocol is called SNMPV1 and described in STD 15, RFC 1157 [8]. A second version of the SNMP message protocol, which is not an Internet standards track protocol, is called SNMPv2c and described in RFC 1901 [9] and RFC 1906 [10]. The third version of the message protocol is called SNMPv3 and described in RFC 1906 [10], RFC 2572 [11] and RFC 2574 [12].

- Protocol operations for accessing management information. The first set of protocol operations and associated PDU formats is described in STD 15, RFC 1157 [8]. A second set of protocol operations and associated PDU formats is described in RFC 1905 [13].

- A set of fundamental applications described in RFC 2573 [14] and the view-based access control mechanism described in RFC 2575 [15].

Managed objects are accessed via a virtual information store, termed the Management Information Base or MIB. Objects in the MIB are defined using the mechanisms defined in the SMI.

This memo specifies a MIB module that is compliant to the SMIv2. A MIB conforming to the SMIv1 can be produced through the appropriate translations. The resulting translated MIB must be semantically equivalent, except where objects or events are omitted because no translation is possible (use of Counter64). Some machine readable information in SMIV2 will be converted into textual descriptions in SMIv1 during the translation process. However, this loss of machine readable information is not considered to change the semantics of the MIB. 


\section{The Directory Services Model.}

The Directory comprises of a set of servers (Directory Servers). Clients or Directory User Agents (DUA) are provided access to the Directory which maybe local or distributed, by the Directory Servers. The server maybe a X.500 Directory system Agent (DSA) [16] running over the OSI suite of protocols or, a (C) LDAP [17,18] frontend to the X.500 Directory System Agent or, a native LDAP Directory Server running directly over TCP or other protocols, or a database acting as a backend to another server, or any other application protocol, or any combination of the above. A Directory Server has one or more application protocol interfaces. Through these interfaces the Directory Server interacts with the DUA and with the peer Directory Servers.

Fig. 1 shows the case of a Directory Server that receives requests and sends back responses in some protocol. Fig. 2 shows one possible scenario where the Directory Server speaks multiple protocols.

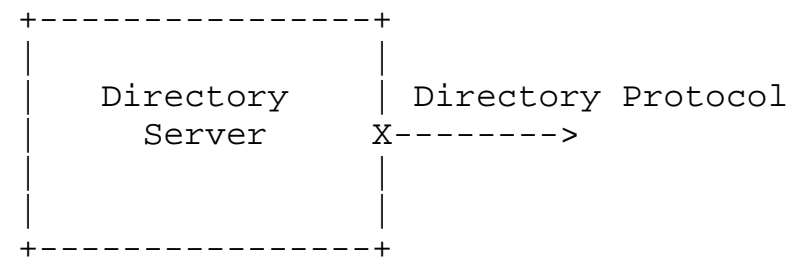

FIG. 1 .

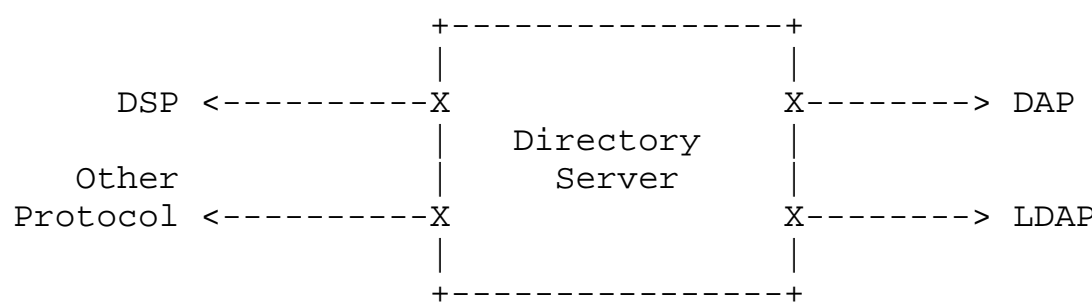

FIG. 2.

The Directory contains information in the form of entries. An entry is a collection of attributes and is uniquely identified by a name, the Distinguished Name (DN). The entries are arranged in a hierarchical tree-like structure called the Directory Information Tree (DIT). 
A DUA requests a Directory Server to perform some operation on the Directory. The Directory server is responsible for performing the operation and after completing its effort to carry out the request, returns a response to the DUA.

A Directory Server may use information stored in its local database or interact with (chain the request to) other Directory servers to service the DUA request. Alternatively, a Directory Server may return a reference to another Directory Server (referral).

The local database of a Directory Server consists of the part of the Directory that is mastered by the Directory Server, the part of the Directory for which it keeps slave copies and cached information that is gathered during the operation of the Directory server.

In the connection oriented mode a DUA "binds" to a Directory Server with a particular identification. The Directory Server may authenticate the identity of the DUA. In the connectionless mode as is employed in CLDAP no binding and/or authentication is carried out between the DUA and the Directory Server. The following type of operations are carried out by the Directory Server : Read, Compare, Addition of an Entry (AddEntry), Modification of an Entry

(ModifyEntry), Modification of a DN (ModifyRDN), Deletion of an Entry (RemoveEntry), List, Search, Abandon. Some Directory Servers do not support some type of operations. For example CLDAP does not support AddEntry, ModifyEntry, ModifyRDN, RemoveEntry etc. In response to requests results and/or errors are returned by the Directory server.

In the distributed Directory data is often replicated to enhance performance and for other advantages. The data to be replicated is transferred from the "Supplier" Directory Server to the "Consumer" Directory Server according to the replication agreement between the supplier and the receiver.

3. MIB Model for Directory Management.

A Directory manager should be able to monitor all the Directory Servers in his/her domain of management. The Directory Servers may be running on one or more hosts and, multiple Directory servers may be running on the same host.

The manager may wish to monitor several aspects of the operational Directory Servers. He/she may want to know the process related aspects - the resource utilization of an operational Directory Server; the network service related aspects e.g. inboundassociations, outbound-associations, operational status, and finally the information specific to the Directory Server application - its operations and performance. 
The MIB defined in this document covers the portion which is specific to Directory services. The network service related part of the MIB, and the host-resources related part of the MIB, as well as other parts of interest to a Manager monitoring the Directory services, are covered in separate documents [19] [20].

The MIB will cover a group of Directory Servers. The grouping will be done on some logical basis by the administrator/manager. In all cases, the grouping will be reflected in the pertinent NETWORKSERVICES-MIB which will have an entry corresponding to each Directory Server in the group.

4. MIB design.

The basic principle has been to keep the MIB as simple as possible. The Managed objects included in the MIB are divided into three tables - dstable, dsApplifopstable, and dsIntTable.

- The dstable contains a list of Directory Servers. The list contains a description of the Directory Servers as well as summary statistics on the entries held by and the cache performance of each Directory Server. The group of servers on this list is likely to contain a part of, if not all, the Directory Servers in the management domain.

- The dsApplifopstable provides summary statistics on the accesses, operations and errors for each application protocol interface of a Directory Server.

- The dsIntTable provides some useful information on the interaction of the monitored Directory Servers with peer Directory Servers.

There are references to the Directory itself for static information pertaining to the Directory server. These references are in the form of "Directory Distinguished Name" [21] of the corresponding object. It is intended that Directory management applications will use these references to obtain further information on the objects of interest.

5. The Directory Server Monitoring MIB.

DIRECTORY-SERVER-MIB DEFINITIONS : := BEGIN

IMPORTS

MODULE-IDENTITY, Counter32, Gauge32, OBJECT-TYPE

FROM SNMPV2-SMI

mib-2 FROM RFC1213-MIB

Displaystring, Timestamp 


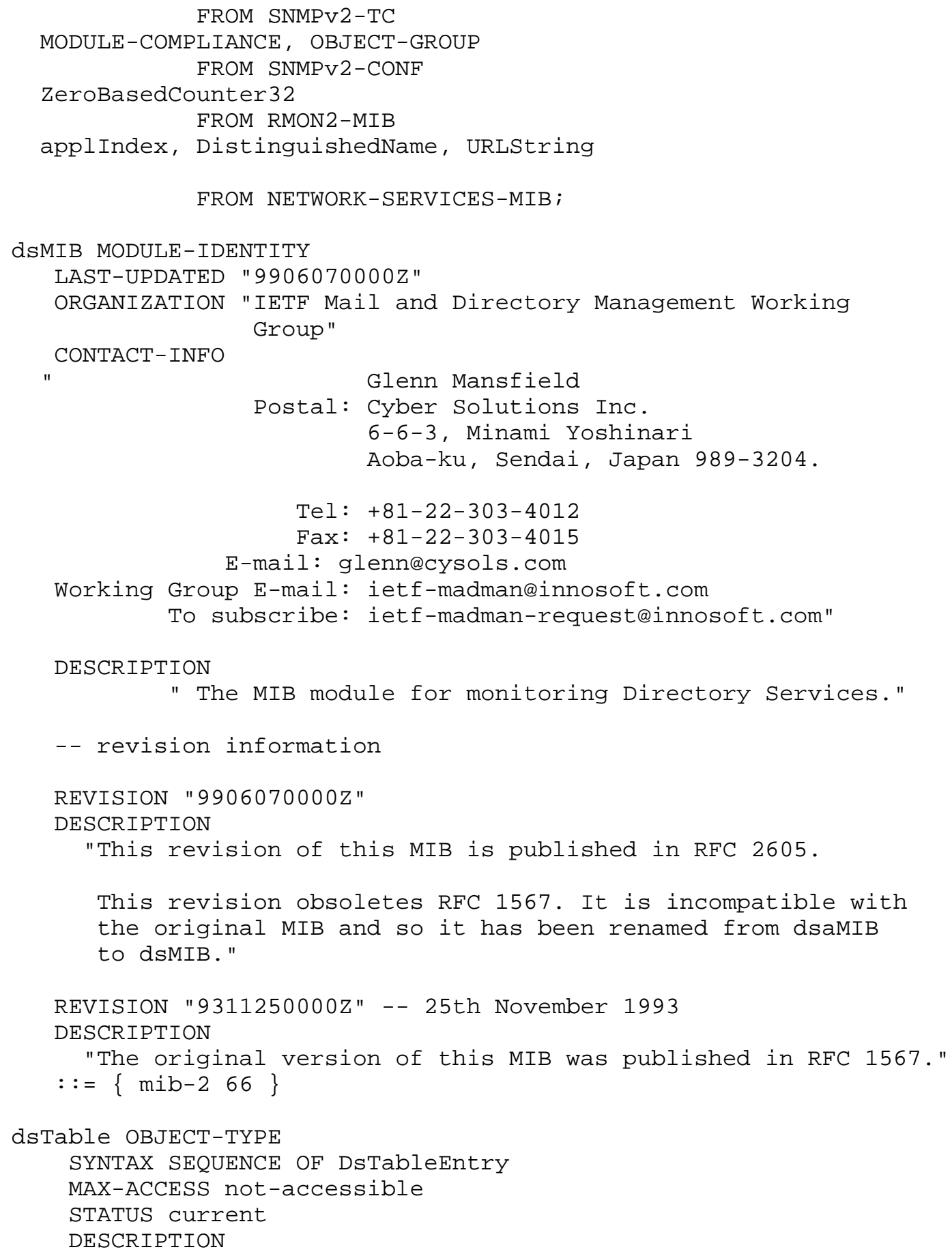


" The table holding information related to the Directory Servers."

$::=\{\mathrm{dsMIB} 1\}$

dsTableEntry OBJECT-TYPE

SYNTAX DsTableEntry

MAX-ACCESS not-accessible

STATUS current

DESCRIPTION

" Entry containing summary description for a Directory Server."

INDEX \{ applIndex $\}$

$::=\{$ dsTable 1$\}$

-- General description of the Directory Server application will be

-- available in the applTable of the NETWORK-SERVICES-MIB indexed by

-- applindex.

DsTableEntry : := SEQUENCE \{

ds ServerType

BITS,

ds ServerDescription

Displaystring,

-- Entry statistics/Cache performance

dsMasterEntries

Gauge 32,

dscopyEntries

Gauge 32,

dsCacheEntries

Gauge 32,

dsCacheHits

counter32,

dsSlaveHits

\}

Counter 32

ds ServerType OBJECT-TYPE

SYNTAX BITS \{

frontEndDirectoryserver (0), backEndDirectoryServer (1)

\}

MAX-ACCESS read-only

STATUS current

DESCRIPTION

"This object indicates whether the server is

a frontend or, a backend or, both. If the server

is a frontend, then the frontEndDirectoryserver 


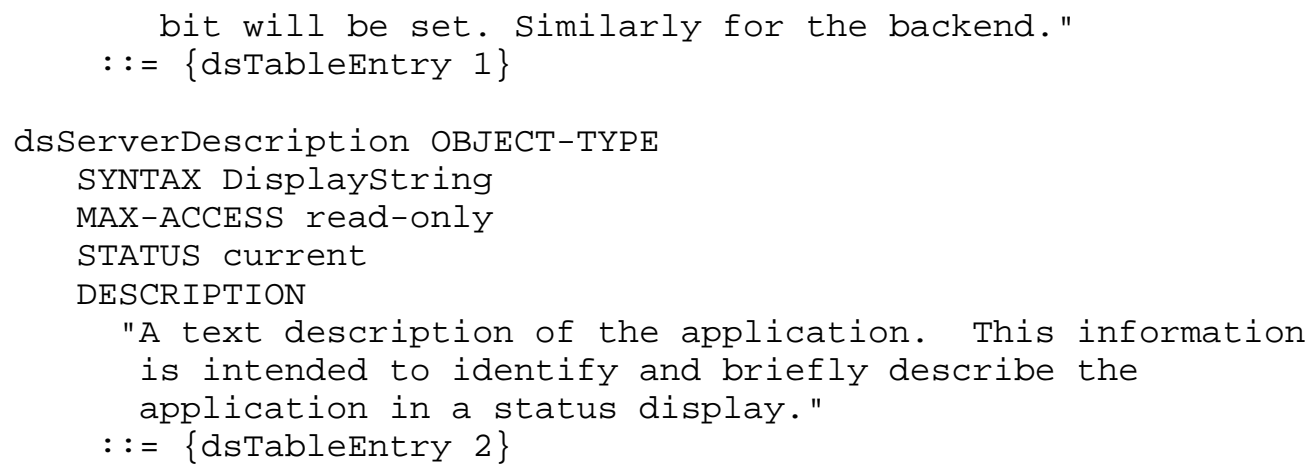




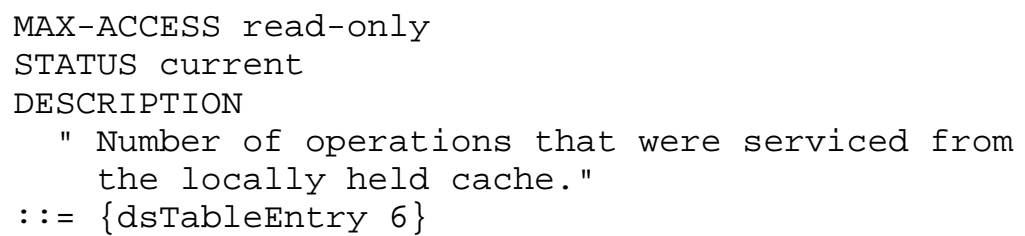




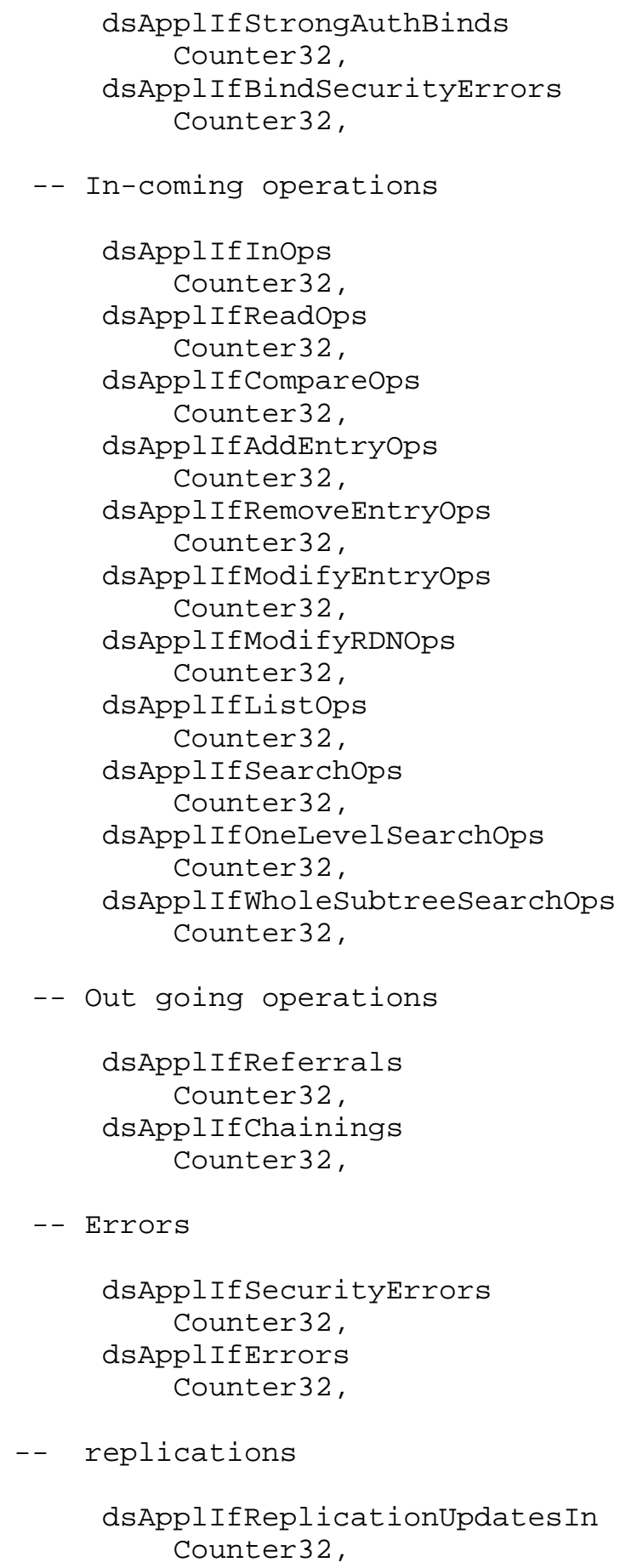




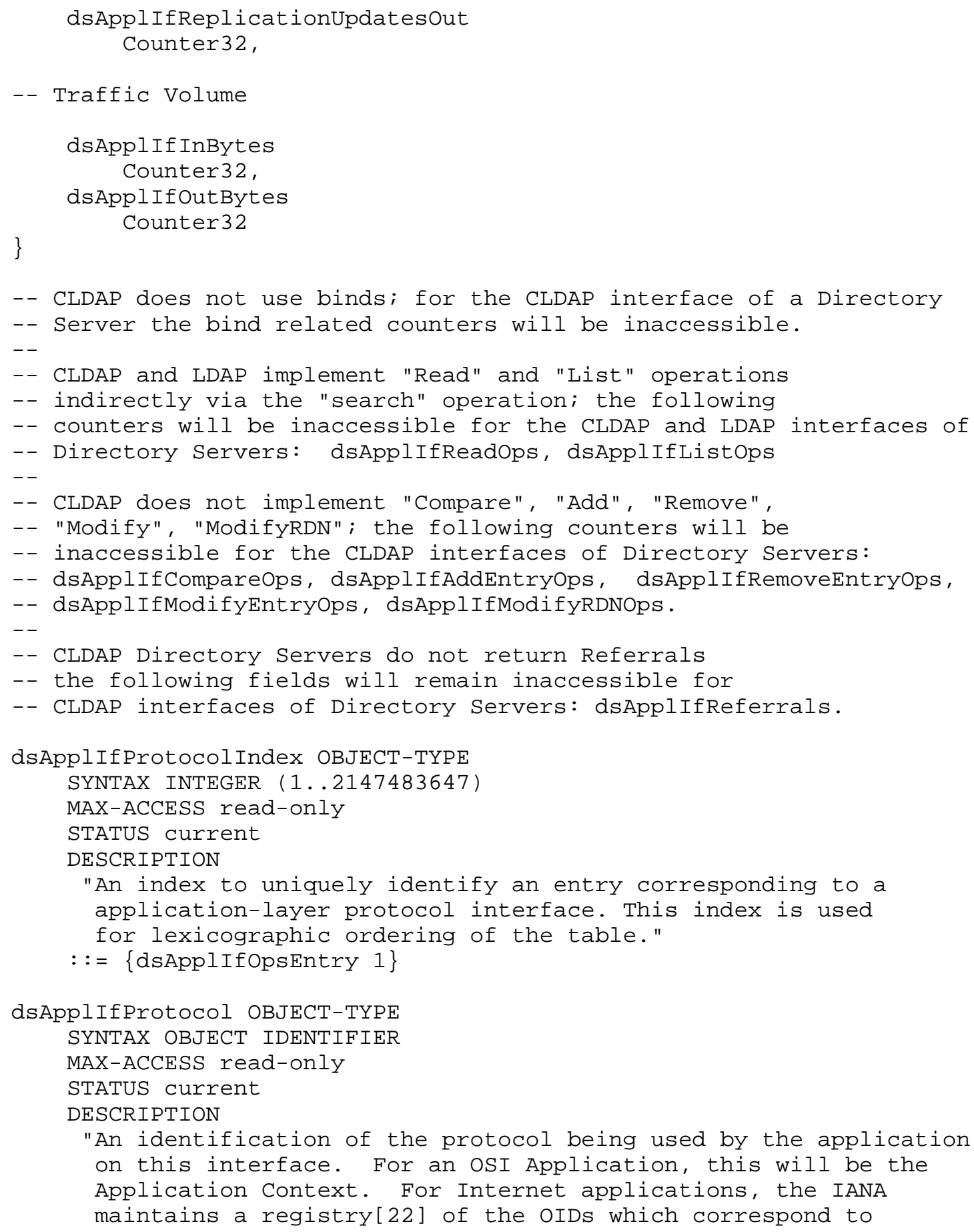




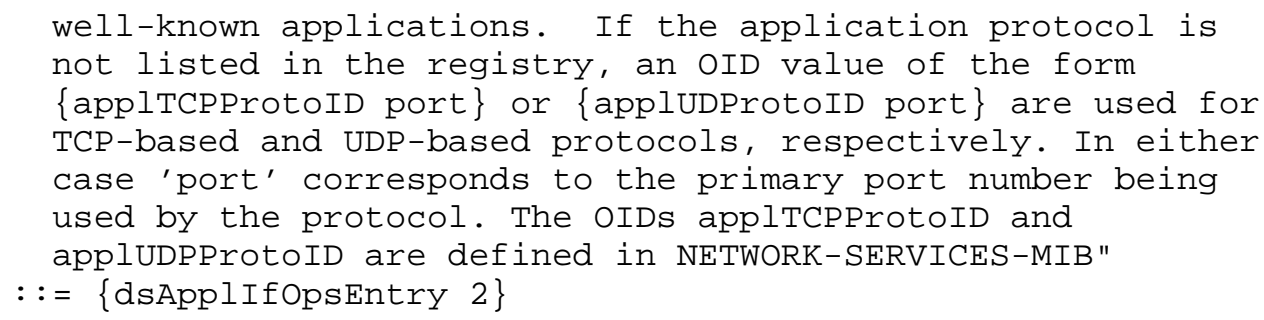

" Number of bind requests that have been rejected due to inappropriate authentication or 


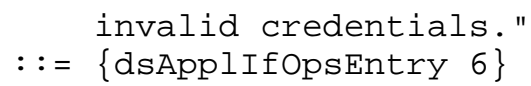


SYNTAX Counter32

MAX-ACCESS read-only

STATUS current

DESCRIPTION

" Number of modifyEntry requests received."

$::=\{$ dsApplifopsEntry 12$\}$

dsApplIfModifyRDNOps OBJECT-TYPE

SYNTAX Counter32

MAX-ACCESS read-only

STATUS current

DESCRIPTION

" Number of modifyRDN requests received."

$::=\{$ dsApplIfOpsEntry 13$\}$

dsApplIfListops OBJECT-TYPE

SYNTAX Counter32

MAX-ACCESS read-only

STATUS current

DESCRIPTION

" Number of list requests received."

$::=\{$ dsApplIfOpsEntry 14$\}$

dsApplifSearchOps OBJECT-TYPE

SYNTAX Counter32

MAX-ACCESS read-only

STATUS current

DESCRIPTION

" Number of search requests- baseobject searches, onelevel searches and whole subtree searches, received."

$::=\{$ dsApplifopsEntry 15$\}$

dsApplIfOneLevel SearchOps OBJECT-TYPE

SYNTAX Counter32

MAX-ACCESS read-only

STATUS current

DESCRIPTION

" Number of oneLevel search requests received." $::=\{$ dsApplifopsEntry 16$\}$

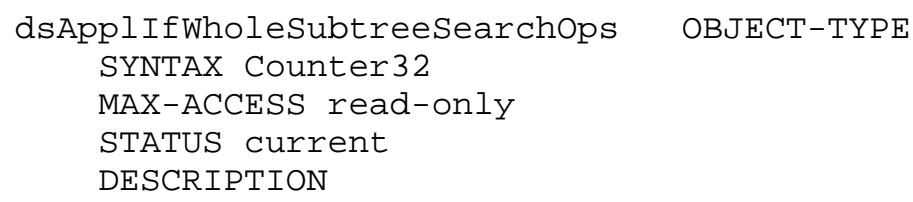




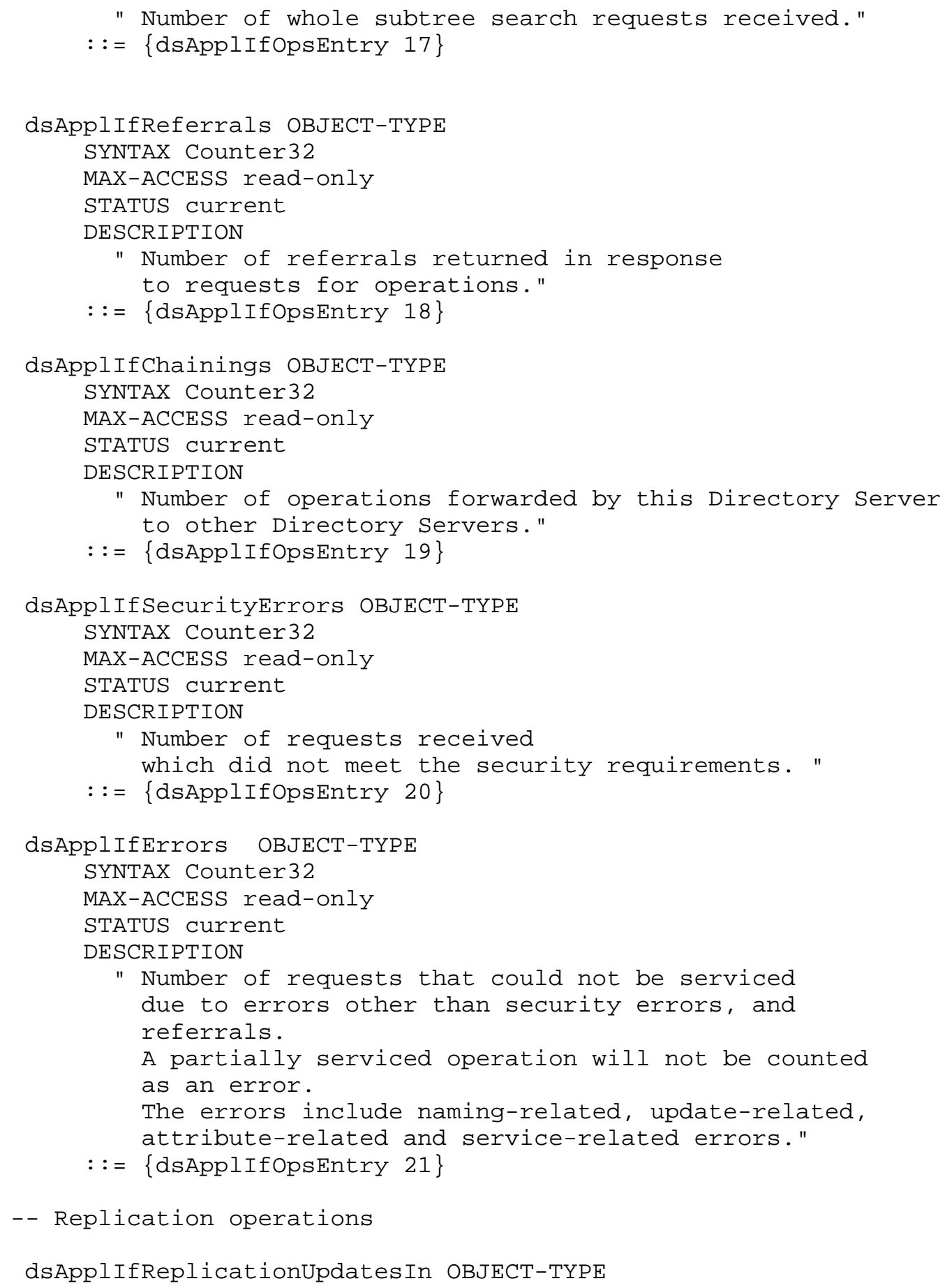




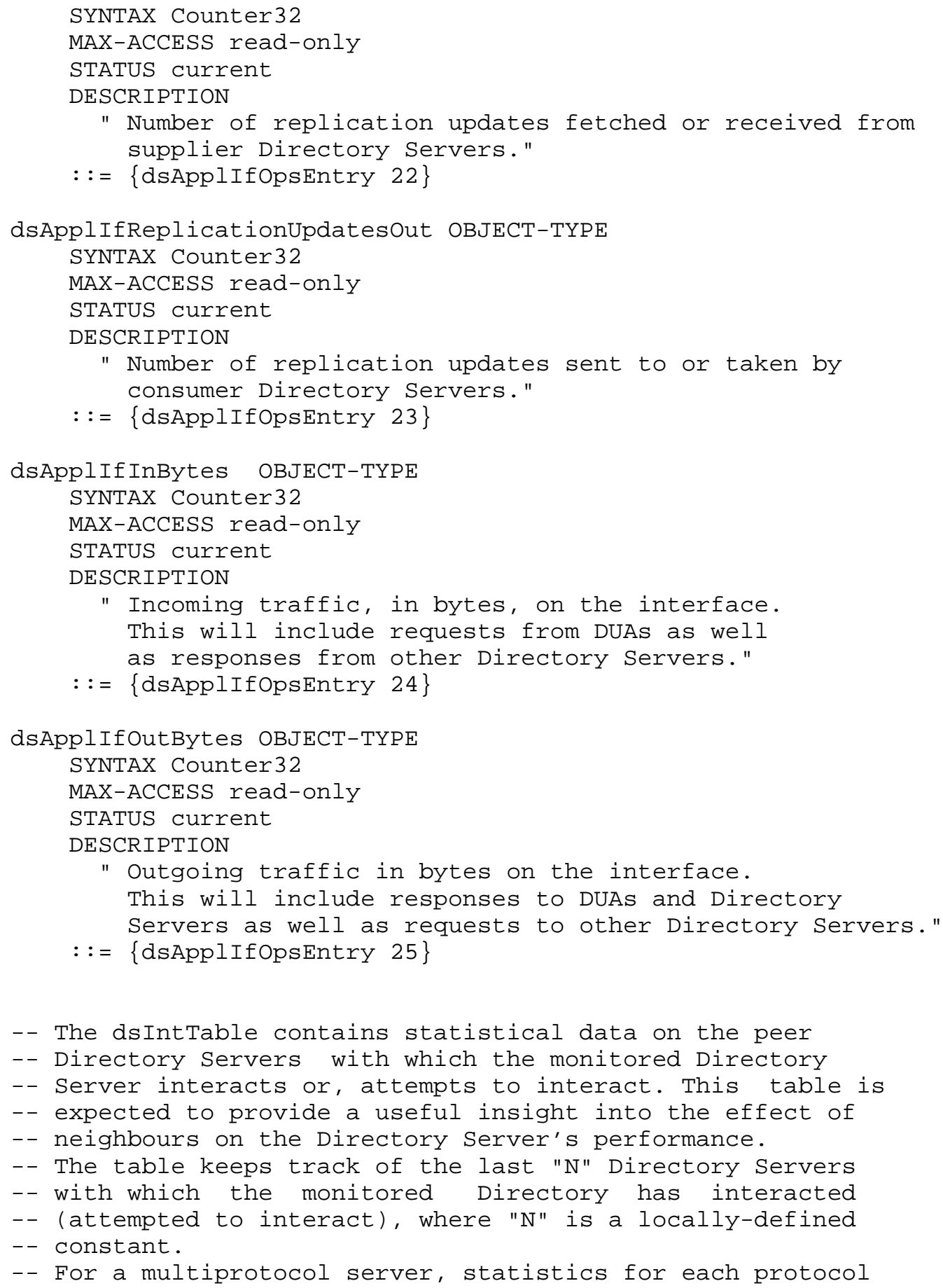




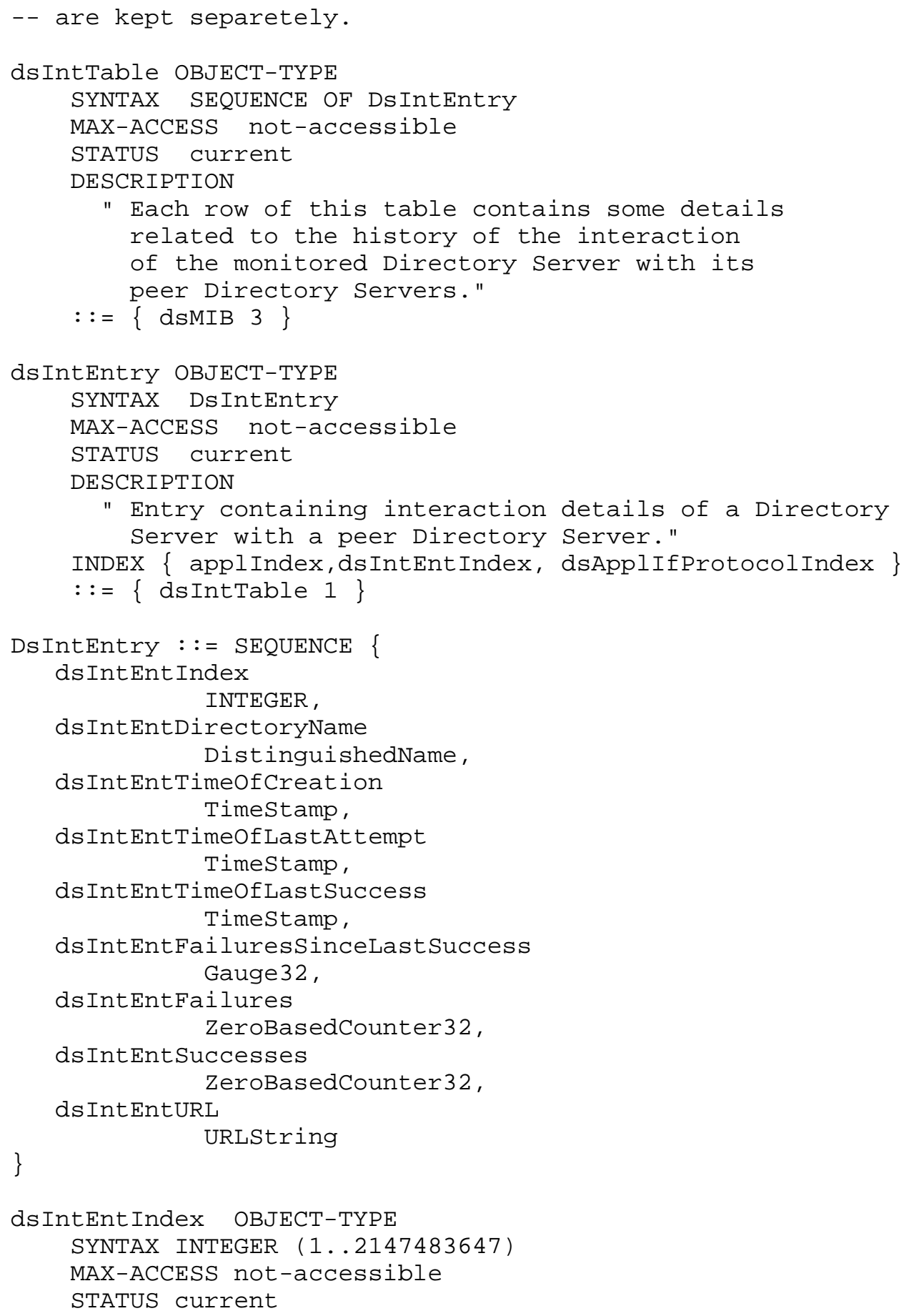




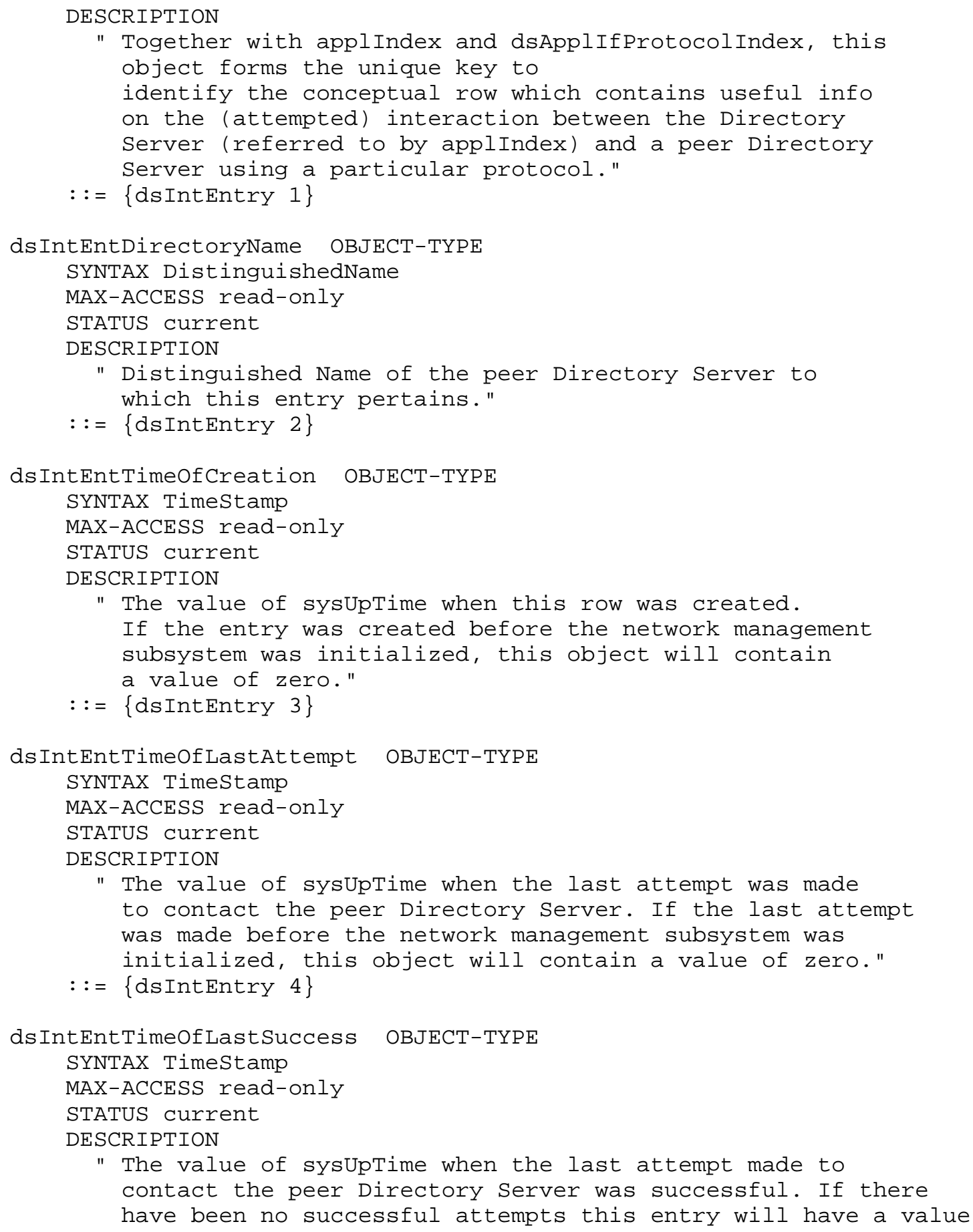




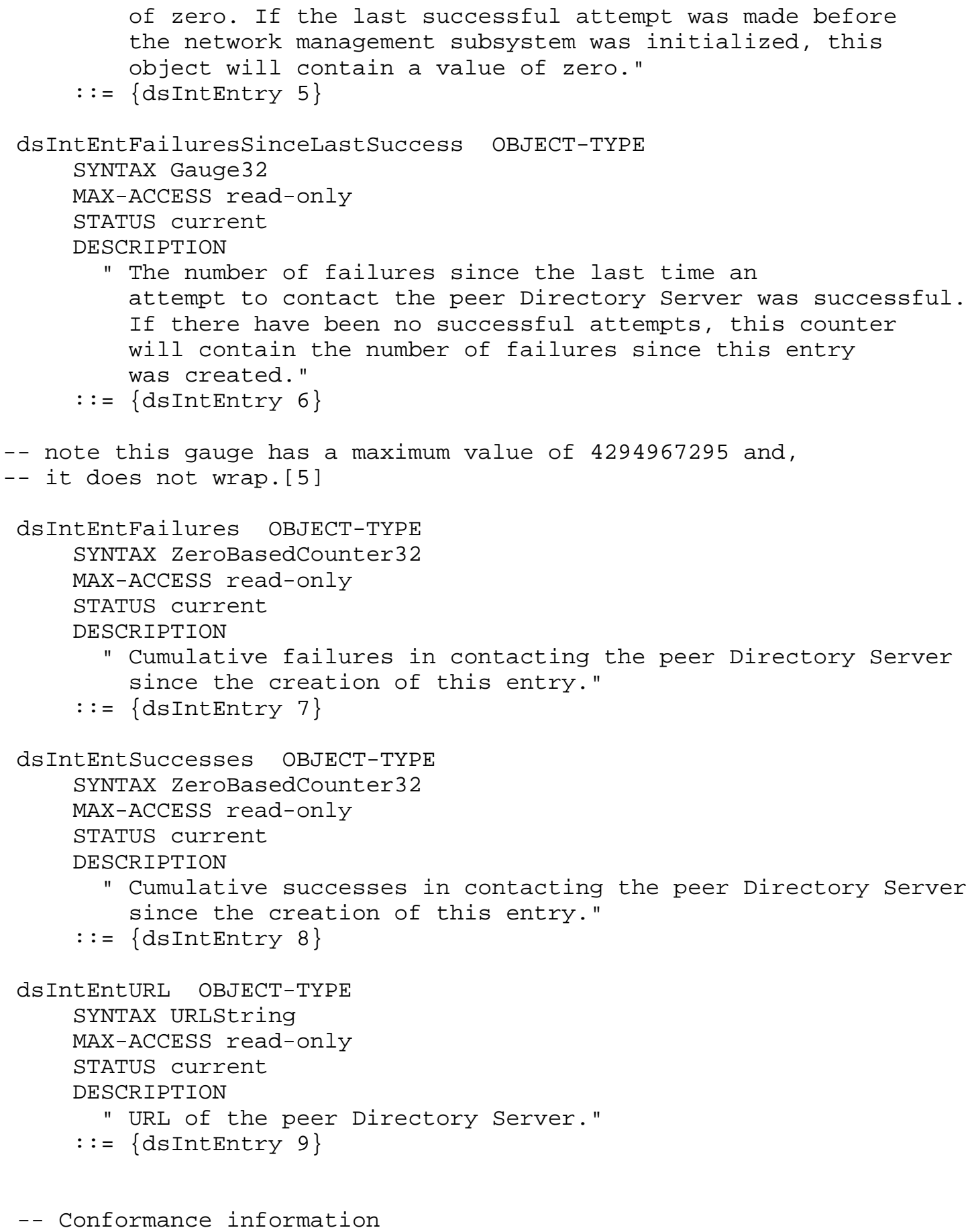




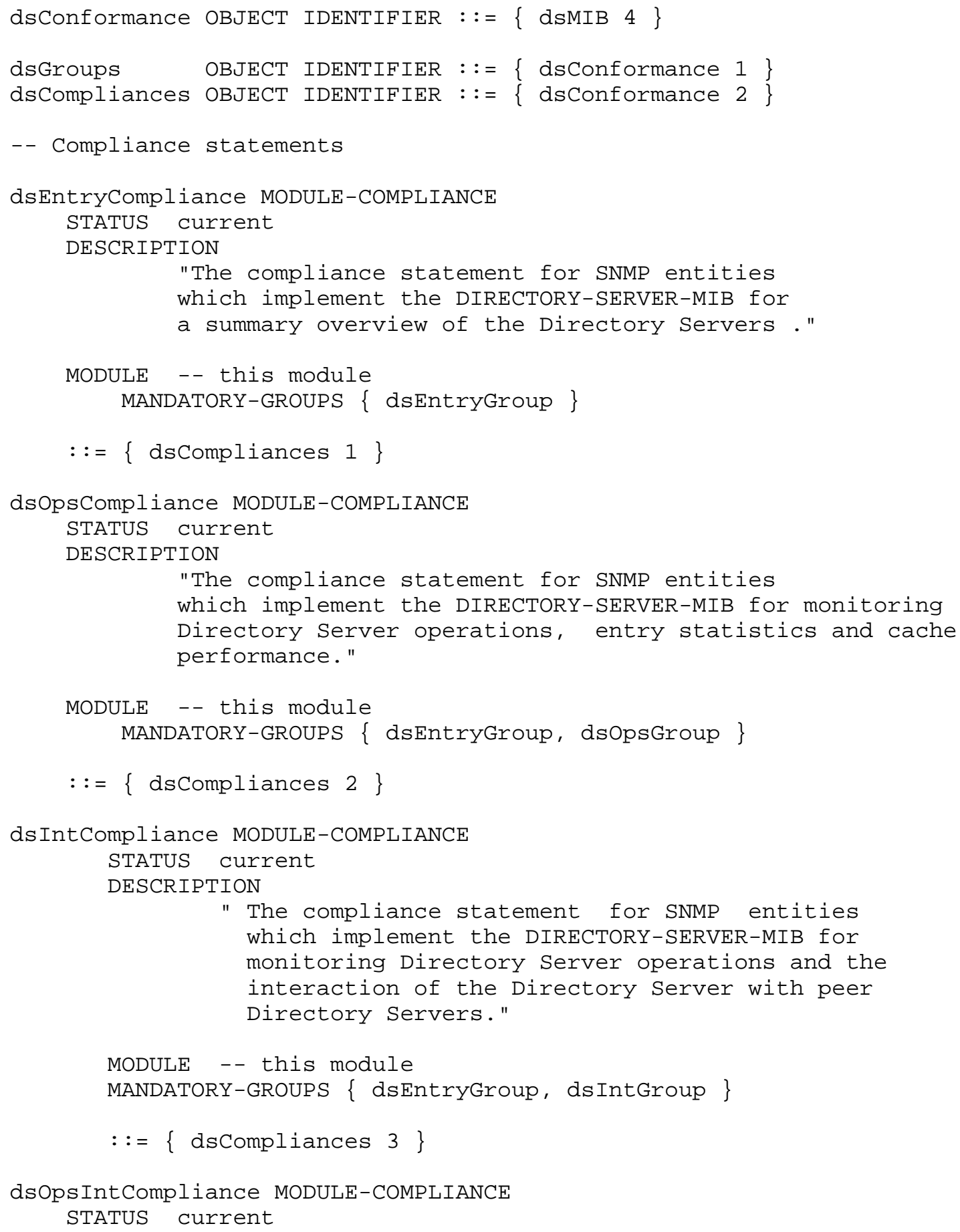




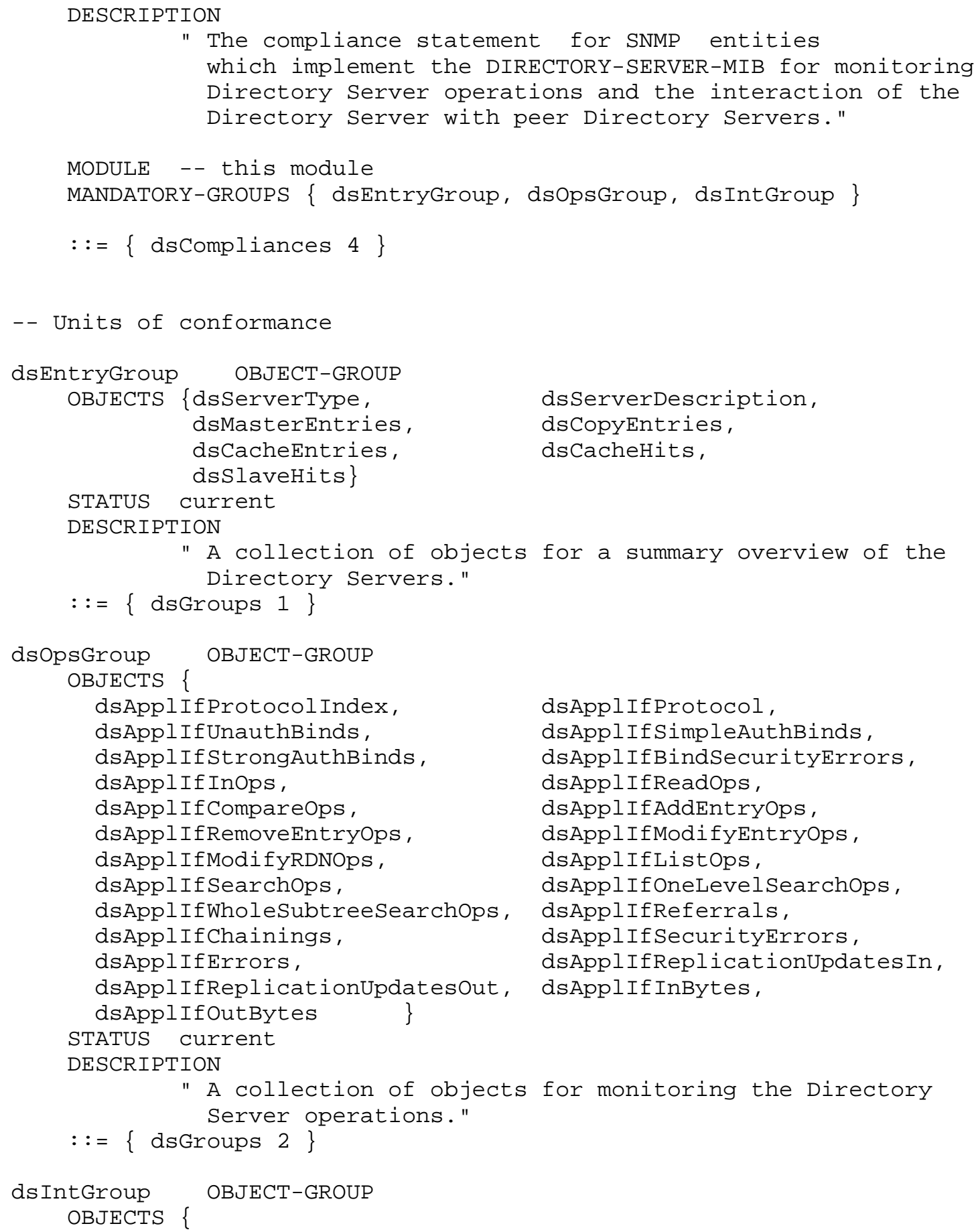




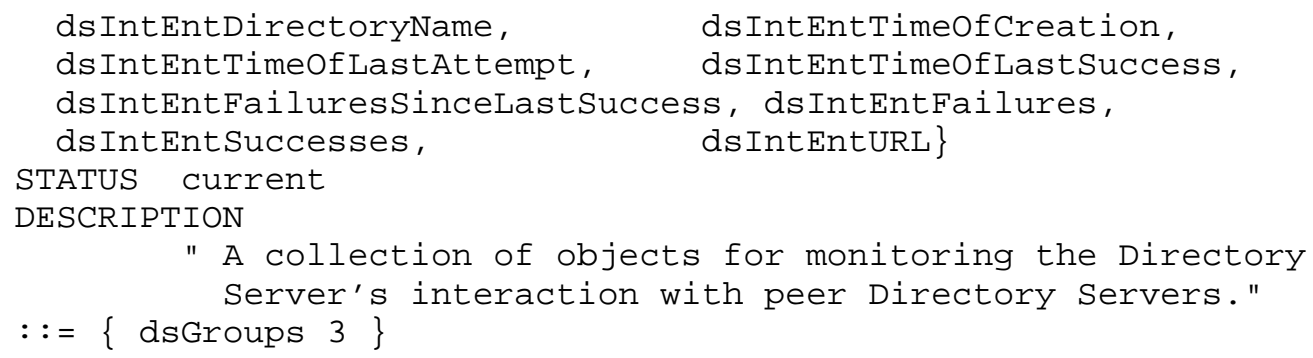

END

6. Intellectual Property

The IETF takes no position regarding the validity or scope of any intellectual property or other rights that might be claimed to pertain to the implementation or use of the technology described in this document or the extent to which any license under such rights might or might not be available; neither does it represent that it has made any effort to identify any such rights. Information on the IETF's procedures with respect to rights in standards-track and standards-related documentation can be found in BCP-11. Copies of claims of rights made available for publication and any assurances of licenses to be made available, or the result of an attempt made to obtain a general license or permission for the use of such proprietary rights by implementors or users of this specification can be obtained from the IETF Secretariat.

The IETF invites any interested party to bring to its attention any copyrights, patents or patent applications, or other proprietary rights which may cover technology that may be required to practice this standard. Please address the information to the IETF Executive Director.

7. Changes from RFC1567.

A more general Directory model in which, several Directory protocols coexist, has been adopted for the purpose of the MIB design. The result is a generic Directory Server Monitoring MIB.

8. Acknowledgements

This memo is the product of discussions and deliberations carried out in the Mail and Directory Management Working Group (ietf-madman-wg). 
References

[1] Harrington, D., Presuhn, R. and B. Wijnen, "An Architecture for Describing SNMP Management Frameworks", RFC 2571, April 1999.

[2] Rose, M. and K. McCloghrie, "Structure and Identification of Management Information for TCP/IP-based Internets", STD 16, RFC 1155, May 1990 .

[3] Rose, M. and K. McCloghrie, "Concise MIB Definitions", STD 16, RFC 1212, March 1991.

[4] Rose, M., "A Convention for Defining Traps for use with the SNMP", RFC 1215, March 1991.

[5] McCloghrie, K., Perkins, D., Schoenwaelder, J., Case, J., Rose, M. and S. Waldbusser, "Structure of Management Information Version 2 (SMIv2)", STD 58, RFC 2578, April 1999.

[6] McCloghrie, K., Perkins, D., Schoenwaelder, J., Case, J., Rose, M. and S. Waldbusser, "Textual Conventions for SMIv2", STD 58, RFC 2579, April 1999.

[7] McCloghrie, K., Perkins, D., Schoenwaelder, J., Case, J., Rose, M. and S. Waldbusser, "Conformance Statements for SMIv2", STD 58, RFC 2580, April 1999.

[8] Case, J., Fedor, M., Schoffstall, M. and J. Davin, "Simple Network Management Protocol", STD 15, RFC 1157, May 1990.

[9] Case, J., McCloghrie, K., Rose, M. and S. Waldbusser, "Introduction to Community-based SNMPv2", RFC 1901, January 1996.

[10] Case, J., McCloghrie, K., Rose, M. and S. Waldbusser, "Transport Mappings for Version 2 of the Simple Network Management Protocol (SNMPv2) ", RFC 1906, January 1996.

[11] Case, J., Harrington D., Presuhn R. and B. Wijnen, "Message Processing and Dispatching for the Simple Network Management Protocol (SNMP)", RFC 2572, April 1999.

[12] Blumenthal, U. and B. Wijnen, "User-based Security Model (USM) for version 3 of the Simple Network Management Protocol (SNMPv3)", RFC 2574, April 1999. 
[13] Case, J., McCloghrie, K., Rose, M. and S. Waldbusser, "Protocol Operations for Version 2 of the Simple Network Management Protocol (SNMPv2)", RFC 1905, January 1996.

[14] Levi, D., Meyer, P. and B. Stewart, "SNMPv3 Applications", RFC 2573, April 1999.

[15] Wijnen, B., Presuhn, R. and K. McCloghrie, "View-based Access Control Model (VACM) for the Simple Network Management Protocol (SNMP) ", RFC 2575, April 1999.

[16] ITU-T Rec. X.501, "The Directory: Models", 1993.

[17] Wahl, M., Howes, T. and S. Kille, "Lightweight Directory Access Protocol (v3)", RFC 2251, December 1997.

[18] Young, A., "Connection-less Lightweight X.500 Directory Access Protocol", RFC 1798, June 1995.

[19] Freed N. and Kille, S., "Network Services Monitoring MIB", RFC 2248, January 1998 .

[20] Grillo, P. and S. Waldbusser, "Host Resources MIB", RFC 1514, September 1993 .

[21] Wahl, W., Kille, S. and T. Howes, "Lightweight Directory Access Protocol (v3): UTF-8 String Representation of Distinguished Names", RFC 2253, December 1997.

[22] http://www.isi.edu/in-notes/iana/assignments/protocol-numbers

Security Considerations

There are no management objects defined in this MIB that have a MAXACCESS clause of read-write and/or read-create. So, if this MIB is implemented correctly, then there is no risk that an intruder can alter or create any management objects of this MIB via direct SNMP SET operations.

However, the information itself may partly reveal the configuration of the directory system and passively increase its vulnerability. The information could also be used to analyze network usage and traffic patterns.

Therefore, it may be important in some environments to control read access to these objects and possibly to even encrypt the values of these object when sending them over the network via SNMP. Not all versions of SNMP provide features for such a secure environment. 
SNMPV1 by itself is such an insecure environment. Even if the network itself is secure (for example by using IPSec), even then, there is no control as to who on the secure network is allowed to access and GET (read) the objects in this MIB.

It is recommended that the implementors consider the security features as provided by the SNMPv3 framework. Specifically, the use of the User-based Security Model RFC 2574 [12] and the View-based Access Control Model RFC 2575 [15] is recommended.

It is then a customer/user responsibility to ensure that the SNMP entity giving access to an instance of this MIB, is properly configured to give access to those objects only to those principals (users) that have legitimate rights to access them.

Authors' Addresses

Glenn Mansfield

Cyber Solutions Inc.

6-6-3 Minami Yoshinari

Aoba-ku, Sendai 989-3204

Japan

Phone: +81-22-303-4012

EMail: glennecysols.com

Steve E. Kille

MessagingDirect Ltd.

The Dome, The Square

Richmond TW9 1DT

UK

Phone: +44-181-332-9091

EMail: Steve.Kille@MessagingDirect.com 
Full Copyright statement

Copyright (C) The Internet Society (1999). All Rights Reserved.

This document and translations of it may be copied and furnished to others, and derivative works that comment on or otherwise explain it or assist in its implementation may be prepared, copied, published and distributed, in whole or in part, without restriction of any kind, provided that the above copyright notice and this paragraph are included on all such copies and derivative works. However, this document itself may not be modified in any way, such as by removing the copyright notice or references to the Internet society or other Internet organizations, except as needed for the purpose of developing Internet standards in which case the procedures for copyrights defined in the Internet Standards process must be followed, or as required to translate it into languages other than English.

The limited permissions granted above are perpetual and will not be revoked by the Internet society or its successors or assigns.

This document and the information contained herein is provided on an "AS IS" basis and THE INTERNET SOCIETY AND THE INTERNET ENGINEERING TASK FORCE DISCLAIMS ALL WARRANTIES, EXPRESS OR IMPLIED, INCLUDING BUT NOT LIMITED TO ANY WARRANTY THAT THE USE OF THE INFORMATION HEREIN WILL NOT INFRINGE ANY RIGHTS OR ANY IMPLIED WARRANTIES OF MERCHANTABILITY OR FITNESS FOR A PARTICULAR PURPOSE.

Acknowledgement

Funding for the RFC Editor function is currently provided by the Internet society. 